J. Perinat. Med. 13 (1985) 227

\title{
The clinical value of measurements of the symphysis-fundus distance and ultrasonic measurements of the biparietal diameter in the di- agnosis of intrauterine growth retardation
}

\author{
S. Cnattingius, O. Axelsson, G. Lindmark
}

Department of Obstetrics and Gynecology, University Hospital, Uppsala, Sweden

\section{Introduction}

The growth retarded infant runs an increased risk of perinatal death and long-term morbidity $[12,22]$. Methods for antenatal identification of intrauterine growth retardation (IUGR) are important.

Clinical evaluation of fetal growth is difficult and often inaccurate. In studies evaluating routine antenatal care, fewer than 50 per cent of the growth retarded infants were suspected $[8,19]$, and for every correct diagnosis there were 2.5 false positive diagnoses [8].

For successful antenatal diagnosis of IUGR, a highly sensitive and simple screening procedure is needed. Accordingly it should be possible to identify a limited risk group which can be supervised more carefully during pregnancy with respect to fetal growth.

The association between the symphysis-fundus (SF) distance and fetal weight has been known since the 1950's [21]. In 1973, when LEROY et al. [11] published a standard curve measuring the SF growth during pregnancy, Westin presented a similar curve in Sweden [26]. The method has also been evaluated by BELIZÁN [1] and Calvert [2]. According to Westin, not only the low but also the static SF curve indicates IUGR [27]. In accordance with CALvert [2], we found that when denoting the

\section{Curriculum vitae}

Sven CNattingius, born in 1949. M.D. 1977. Specialist in Obstetrics and Gynecology 1982. At present registered physician, Department of Obstetrics and Gynecology, University Hospital, Uppsala, Sweden.

static SF curve as pathological, the number of false positive cases were substantially increased [4].

The SF curve has been in routine use at the majority of the Swedish antenatal care clinics since the mid-seventies. Practically all pregnant women visit these clinics regularily.

Lately, repeated ultrasonic measurements of fetal dimensions have given us new possibilities to estimate fetal growth. It seems doubtful if this method can be used for screening purposes since it requires a specialized staff and expensive equipment. Furthermore, as in general, when a new diagnostic method is introduced, the primary concern has been to show 
that it is useful for the specific diagnosis requested, rather than to show that is adds new information or is superior to the diagnostic methods already in common use. When repeated ultrasonic measurements of the biparietal diameter (BPD) were introduced in Sweden as a method to detect fetal growth disturbances, it was assumed rather than demonstrated that this instrument was superior to the SF curve in predicting growth retarded infants [16]. Repeated ultrasonic BPD measurements were the first and are probably still the most commonly used ultrasonic method of estimating fetal growth [3].

In this report, the diagnostic efficiency of the SF curve in predicting IUGR is compared with that of repeated ultrasonic BPD measurements.

\section{Materials and methods}

This study was performed in Uppsala County, Sweden. Since June 1979 a program has been in use for the follow-up of pregnant women with risk factors for IUGR [5]. In 1980, 3,022 Scandinavian women from the County delivered live singleton born infants at the University Hospital, Uppsala. In 377 pregnancies with risk factors, fetal growth was followed by repeated measurements of the symphysisfundus distance (SF) as well as with repeated ultrasonic measurements of the biparietal diameter (BPD). Only these patients were included in the present study. SF measurements were performed by the midwives at the antenatal care clinics, according to the directions by WESTIN [28]. Measurements were performed every second week from the 20th to the 36th week and thereafter weekly. A SF curve with at least one measurement three or more $\mathrm{cm}$ below the mean of the normal curve was considered as pathological [4].

The ultrasonic BPD measurements (sound velocity $1,540 \mathrm{~m} / \mathrm{sec}$.) were performed by two specially trained assistents with four years experience with the technique. The measurements were made according to CAMPBELL [3]. The first measurement was performed between the 16th and 21st gestational week. The second BPD measurement, done at least ten weeks after the first, was performed within the zone of linear BPD growth (i. e. before the 33 rd gestational week [16]). If the mean weekly increase was $\leq 2.85 \mathrm{~mm}$, BPD growth was assessed as pathological [16]. In term pregnancies (gestational age $\geq 36$ completed weeks, $n=358$ ), a third measurement was performed between week 37 and term. BPD growth was also assessed as pathological if this measurement was $2 \mathrm{SD}$ or more below the mean of the Swedish BPD growth curve $[17,18]$.

\section{Definitions:}

Gestational age: In completed weeks according to the first performed ultrasonic BPD measurement [7].

Moderate growth retardation: Birthweight for gestational age $\leq-1 \mathrm{SD}$ and above $-2 \mathrm{SD}$ from the mean, according to the Swedish growth curves used [9].

Severe growth retardation: Birthweight for gestational age $\leq-2 \mathrm{SD}$ from the mean according to the Swedish growth curves.

The sensitivity (\%) of a method in indicating IUGR was defined as:

True positive $\times 100$

True positive + false negative

The specificity (\%) was defined as:

True negative $\times 100$

$\overline{\text { True negative }+ \text { false positive }}$

The predicted value of a positive test (\%) was defined as:

True positive $\times 100$

True positive + false positive

The predicted value of a negative test (\%) was defined as:

True negative $\times 100$

True negative + false negative 


\section{Results}

There were ten severely growth retarded infants delivered by the studied women $(\mathrm{n}=377)$. As demonstrated in Fig. 1, pathological SF curves occurred in 40 pregnancies (ten true positive and 30 false positive). Pathological BPD growth occurred in 79 pregnancies (seven true positive and 72 false positive). In 85 cases ( 23 per cent) the methods contradicted each other with respect to fetal growth. Both tests were assessed as pathological in 17 pregnancies. From this group, seven severely growth retarded infants were delivered. No severely growth retarded infant was delivered when both tests were assessed as normal.

\begin{tabular}{|r|r|r|r|}
\hline SF & pathological & normal & totals \\
\hline pathological & $\begin{array}{r}17 \\
(41 \%)\end{array}$ & $\begin{array}{r}0 / 62 \\
(0 \%)\end{array}$ & $\begin{array}{r}7 / 79 \\
(9 \%)\end{array}$ \\
\hline normal & $\begin{array}{c}3 / 23 \\
(13 \%)\end{array}$ & $\begin{array}{r}0 / 275 \\
(0 \%)\end{array}$ & $\begin{array}{r}3 / 298 \\
(1 \%)\end{array}$ \\
\hline totals & $\begin{array}{r}10 / 40 \\
(25 \%)\end{array}$ & $\begin{array}{r}0 / 337 \\
(0 \%)\end{array}$ & $\begin{array}{r}10 / 377 \\
(3 \%)\end{array}$ \\
\hline
\end{tabular}

Fig. 1. Test results for women delivering severely growth retarded infants, in relation to the total number of women with different combinations of test results.

Thirty-nine severely or moderately growth retarded infants were delivered. Fig. 2 shows that 48 per cent $(19 / 40)$ of women with pathological SF curves delivered severely or moderately growth retarded infants. When BPD growth was assessed as pathological, only 22 per cent (17/79) delivered severely or moderately growth retarded infants. When both tests were assessed as pathological, 71 per cent (12/17) delivered severely or moderately growth retarded infants. On the other hand, 38 per cent $(15 / 39)$ of the severely or moderately growth retarded infants

\begin{tabular}{|l|l|l|l|}
\hline SF & pathological & normal & totals \\
\hline pathological & $\begin{array}{r}12 / 17 \\
(71 \%)\end{array}$ & $\begin{array}{r}5 / 62 \\
(8 \%)\end{array}$ & $\begin{array}{r}17 / 79 \\
(22 \%)\end{array}$ \\
\hline normal & $\begin{array}{r}7 / 23 \\
(30 \%)\end{array}$ & $\begin{array}{r}15 / 275 \\
(5 \%)\end{array}$ & $\begin{array}{r}22 / 298 \\
(7 \%)\end{array}$ \\
\hline totals & $\begin{array}{r}19 / 40 \\
(48 \%)\end{array}$ & $\begin{array}{r}20 / 337 \\
(6 \%)\end{array}$ & $\begin{array}{r}39 / 377 \\
(10 \%)\end{array}$ \\
\hline
\end{tabular}

Fig. 2. Test results for women delivering severely or moderately growth retarded infants, in relation to the total number of women with different combinations of test results.

were delivered by mothers with both tests normal.

The validity of SF measurements in predicting IUGR was compared with that of BPD measurements. As is demonstrated in Tab. I, the diagnostic efficiency of the SF curve was higher than that of repeated BPD measurements.

Tab. I. Validity of repeated SF and BPD measurements for standardized birthweight $\leqq-2$ SD and standardized birthweight $\leqq-1 \mathrm{SD}$.

Standardized birthweight

$\leqq-2 \operatorname{SD}(\mathrm{n}=10)$

\begin{tabular}{rrr} 
& SF & BPD \\
\hline$\%$ & 100 & 70 \\
$\%$ & 92 & 80 \\
$\%$ & 25 & 9 \\
$\%$ & 100 & 99
\end{tabular}

sensitivity

specificity

Predictive value of

a positive test

Predictive value of

a negative test

Standardized birthweight

$\leqq-1 \mathrm{SD}(\mathrm{n}=61)$

sensitivity

specificity

$\% \quad 49 \quad 44$

predictive value of

a positive test

$\% \quad 94$

82

predictive value of

a negative test

$\% \quad 48$

22

$\% \quad 94$

93 


\section{Discussion}

In clinical practice, when the obstetrician faces a pathological BPD or SF measurement, he is usually disposed to rely more on the technically advanced method. However, we found that the clinical value of the SF curve was better than that of ultrasonic BPD measurements in the diagnosis of IUGR. In accordance to a recently published Swedish study [23], we found the number of false positive cases to be unacceptably high when using repeated ultrasonic BPD measurements to detect IUGR. Furthermore, the BPD measurements have a disadvantage in that they will above all detect the symmetrical type of IUGR, which probably includes many healthy genetically small infants [10]. Symmetrical IUGR may also be caused by chronic maternal malnutrition, intrauterine infections or chromosomal anomalies [20]. However, when these conditions are diagnosed in late pregnancy, the possibilities of practical therapy are very limited.

The SF curve is used as a measure of uterine growth. Therefore, SF measurements are probably low in both symmetric and assymmetric IUGR, and especially in cases with oligohydramnion, which is of clinical importance. Like previous investigators, we found neither method to be ideal in diagnosing IUGR $[1,2,14,16,24]$. The methods contradicted each other frequently, which may lead the clinician to abandon his first suspicion.

The number of severely growth retarded infants were low $(n=10)$. Although all these infants were delivered by mothers with pathological SF

\section{Summary}

The diagnostic efficiency in the prediction of intrauterine growth retardation (IUGR) of repeated measurements of the symphysis-fundus (SF) distance and repeated ultrasonic measurements of the biparietal diameter (BPD) was investigated in 377 pregnancies, all at risk for IUGR.

Measurements of the SF distance were found to be more effective than ultrasonic BPD measurements for antenatal diagnosis of IUGR. For every correct diagnosis there were three false positive when using SF meas- curves, this should be regarded with scepticism. Previous studies report that the majority, but not all, of the growth retarded infants are delivered by mothers exhibiting pathological SF curves $[1,2,24,27]$. In accordance to previous studies $[1,2]$, the results obtained indicate that the number of false positive cases is unacceptably high, when using the SF curve as a diagnostic instrument for IUGR. Instead, the SF curve should mainly be used as a screening instrument for severe IUGR.

When the SF curve is assessed as pathological, other methods should be used. However, if repeated BPD measurements are the only ultrasonic method in routine use, one should consider to do without this method. The rapid progress in ultrasound technology has given us new methods of diagnosing IUGR, such as measurements of the fetal abdominal diameter or crown-rump length $[15,18]$, total intrauterine volume [6] or amniotic fluid volume [13]. Although reported as very successful, these ultrasonic measurements require considerable skill and have so far neither been proved to be more effective than the SF method for antenatal diagnosis of IUGR [25], nor demonstrated to improve perinatal outcome [14]. Hence, the final step in the diagnosis of IUGR is not obvious to-day. However, if not only the SF curve but also late ultrasonic measurements are assessed as pathological, this will further confirm the suspicion of IUGR. Therefore, we recommend late ultrasonic measurements (including other fetal dimensions than BPD), in cases with pathological SF curves.

Keywords: Fetal growth retardation, human pregnancy, screening, symphysis-fundus distance, ultrasonographic measurement.

urements and ten when using ultrasonic BPD measurements. When the SF method is used, repeated ultrasonic BPD measurements add very little information. The SF curve is a very simple and inexpensive method and should be used as a screening instrument for severe IUGR. When the SF curve is assessed as pathological, ultrasonic measurements also including other fetal dimensions than only BPD are recommended as a way of diagnosing IUGR. 


\section{Zusammenfassung}

Der klinische Wert von Messungen des Symphysen-Abstands und Ultraschallmessungen des biparietalen Durchmessers für die Diagnose einer intrauterinen Wachstumsverzögerung

Bei 377 Schwangerschaften, in denen ein Risiko für eine intrauterine Wachstumsretardierung (IUGR) vorlag, wurde die diagnostische Effizienz von wiederholten Messungen des Abstands zwischen Symphyse und Fundus (SF) und wiederholten Ultraschallmessungen des biparietalen Durchmessers (BPD) für die Vorhersage einer IUGR untersucht.

Messungen des SF-Abstands sind für die pränatale Diagnose einer IUGR effektiver als US-Messungen des
BPD. Auf jede korrekte Diagnose ergaben sich drei falsch-positive Ergebnisse bei Anwendung der SF-Messungen und zehn bei Anwendung der BPD-Messungen. Bei Benutzung der SF-Methode ergeben wiederholte USMessungen des BPD sehr wenig an zusätzlicher Information. Da die Messung des SF-Abstands eine sehr einfache und kostensparende Methode ist, sollte die SF-Kurve als Screening für eine IUGR angewendet werden. In den Fällen, in denen sich die SF-Kurve als pathologisch erweist, werden US-Messungen, die neben dem BPD auch andere Parameter umfassen, für die Diagnose einer IUGR empfohlen.

Schlüsselwörter: Fetale Wachstumsverzögerung, Schwangerschaft beim Menschen, Screening, Symphysen-FundusAbstand, Ultraschallmessungen.

\section{Résumé}

Intérêt clinique des mesures de la distance symphyse pubienne - fond utérin et des mesures échographiques du diamètre bipariétal, en vue de diagnostiquer un retard de croissance intra-utérin

Nous avons étudié le rendement diagnostique, en vue de prédire un retard de croissance intra-utérin (R. C. I. U.), de mesures répétées de la hauteur utérin (H. U.) et de mesures ultra-sonores répétées du diamètre bipariétal (B. I. P.) au cours de 377 grossesses toutes à risque de R. C. I. U.

Les mesures de la $H$. U. s'avèrent plus opérantes que les mesures ultra-sonores du B. I. P., en ce qui concerne le diagnostic prénatal d'un R. C. I. U. Pour chaque diagnostic correct nous avons enregistré trois faux positifs, en utilisant la méthode des mesures de la $\mathrm{H}$. U. et dix faux positifs, en utilisant la méthode des mesures ultrasonores du B. I. P. Quand on se sert de la méthode de la $H$. U., des mesures ultra-sonores répétées donnent très peu d'information supplémentaire. Comme les mesures de la $H$. U. constituent une méthode très simple et très peu coûteuse, la courbe de $H$. U. doit être utilisée comme instrument de dépistage de graves R.C.I.U. Lorsque la courbe de $H$. U. est estimée pathologique, il est recommandé d'avoir recours à des mesures ultrasonores comprenant aussi d'autres dimensions fotales que le seul B. I. P., en vue de diagnostiquer un éventuel R. C. I. U.

Mots-clés: Dépistage, grossesse, hauteur utérine, mesure échographique, retard de croissance fœtale.

Acknowledgements: This study was supported financially by grants from Stiftelsen Allmänna Barnbördshusets Minnesfond and Stiftelsen Margaretahemmet.

\section{Bibliography}

[1] Belizán, J. M., J. Villar, J. C. Nordin, J. Malamud, L. S. DE VICUna: Diagnosis of intrauterine growth retardation by a simple clinical method: Measurement of uterine height. Am. J. Obstet. Gynecol. 13 (1978) 643

[2] Calvert, J. P., E. E. Crean, R. G. Newcombe, J. F. PEARSON: Antenatal screening by measurements of symphysis-fundus height. Br. Med. J. 285 (1982) 846

[3] Campbell, S.: An improved method of fetal cephalometry by ultrasound. J. Obstet. Gynaecol. Brit. Cwlth. 75 (1968) 568
[4] Cnattingius, S., O. Axelsson, G. Lindmark: Symphysis-fundus measurements and intrauterine growth retardation. Acta Obstet. Gynecol. Scand. 63 (1984) 335

[5] Cnattingius, S., O. Axelsson, G. Eklund, G. LINDMARK: Early pregnancy screening for intrauterine growth retardation. Early Hum. Dev. 10 (1984) 35

[6] Gohari, P., R. L. Berkowitz, J. C. Hobbins: Prediction of intrauterine growth retardation by determination of total intrauterine volume. Am. J. Obstet. Gynecol. 127 (1977) 255 
[7] Grennert, L., P.-H. Persson, G. Gennser: Benefits of ultrasonic screening of a pregnant population. Acta Obstet. Gynecol. Scand. Suppl. 78 (1978) 5

[8] Hall, M. H., P. K. CHNG: Is routine antenatal care worth while? Lancet ii (1980) 78

[9] Karlberg, P., L. Engström, U. Selstam: Normal range curves for Swedish infants. Gothenburg 1979

[10] KIERSE, M. J. N. C.: Aetiology of intrauterine growth retardation. In: VAN ASSCHE, F. A., W. B. ROBERTSON (eds.): Fetal growth retardation. Churchill, Livingstone, Edinburgh-LondonMelbourne-New York 1981

[11] LEROY, B., F. LEFORT, H. KAMKAR: Hauteur utérine et perimètre ombilícal. Indices de developpement utérin. Rev. Fr. Gynecol. 2 (1973) 83

[12] Low, J. A., R. S. Gailbraight: Pregnancy characteristics of intrauterine growth retardation. Obstet. Gynecol. 44 (1974) 122

[13] Manning, F. A., L. M. Hill, L. D. Platt: Qualitative amniotic fluid volume determination by ultrasound.: Antepartum detection of intrauterine growth retardation. Am. J. Obstet. Gynecol. 139 (1981) 254

[14] National Institutes of Health: The use of diagnostic ultrasound imaging in pregnancy. Report from a consensus development conference. Feb. 6-8, 1984

[15] Neilson, J. P., C. R. Whitfield, T. C. Aitchinson: Screening for the small for dates fetus: A two-stage ultrasonic examination schedule. Br. Med. J. May 17 (1980) 1203

[16] Persson, P.-H., L. Grennert, G. Gennser: Diagnosis of intrauterine growth retardation by serial ultrasonic cephalometry. Acta Obstet. Gynecol. Scand. [Suppl.] 78 (1978) 40

[17] Persson, P.-H., L. Grennert, G. Gennser, B. GullberG: Normal range curves for the intrauterine growth of the biparietal diameter. Acta Obstet. Gynecol. Scand. [Suppl.] 78 (1978) 15
[18] Persson, P.-H., S. Kullander: Long-term experience of general ultrasound screening in pregnancy. Am. J. Obstet. Gynecol. 146 (1983) 942

[19] RosenberG, K., J. M. Grant, M. HepburN: Antenatal detection of growth retardation: actual practice in a large maternity hospital. Br. J. Obstet. Gynaecol. 89 (1982) 12

[20] Rosso, P., M. WINICK: Intrauterine growth retardation. A new systematic approach based on the clinical and biochemical characteristics of this condition. J. Perinat. Med. 2 (1974) 147

[21] Rumbolz, W. L., L. S. McGoogan: Placental insufficiency and the small undernourished full-term infant. Obstet. Gynecol. 1 (1953) 294

[22] SABEL, K.-G., R. Olegærd, L. Victorin: Remaining sequele with modern perinatal care. Pediatrics 57 (1976) 652

[23] Selbing, A., K. Wichman, G. Ryden: Screening for detection of intrauterine growth retardation by means of ultrasound. Acta Obstet. Gynecol. Scand. 63 (1984) 543

[24] Wallin, A., E. Gyllenswärd, B. Westin: Symphysis-fundus measurements in prediction of fetal growth disturbances. Acta Obstet. Gynecol. Scand. 60 (1981) 317

[25] Warsof, S. L., J. M. Pearce, S. Campbell: The present place of routine ultrasound screening. Clin. Obstet. Gynaecol. 10 (1983) 445

[26] Westin, B.: Graviditetsövervakning med gravidogram. In: Graviditets och fosterövervakning, 2 (1973) 25. Svensk Gynekologisk förening, Falun

[27] Westin, B.: Gravidogram and fetal growth. Acta Obstet. Gynecol. Scand. 56 (1977) 273

[28] Westin, B.: Spri, Publ. Project 3033 (1977)

Received June 9, 1984. Revised November 12, 1984. Accepted November 15, 1984.

Dr. Sven Cnattingius
Department of Obstetrics and Gynecology
University Hospital
S-751 85 Uppsala, Sweden
University Hospital -751 85 Uppsala, Sweden 